\title{
The Ontological Backlash: Why did Mainstream Analytic Philosophy Lose Interest in the Philosophy of History?
}

\author{
Giuseppina D'Oro
}

\begin{abstract}
This paper seeks to explain why mainstream analytic philosophy lost 12 interest in the philosophy of history. It suggests that the reasons why the philosophy 13 of history no longer commands the attention of mainstream analytical philosophy may be explained by the success of an ontological backlash against the linguistic 15 turn and a view of philosophy as a form of conceptual analysis. In brief I argue that 16 in the 1950s and 1960s the philosophy of history attracted the interest of mainstream analytical philosophers because the defence of the autonomy of historical 17 18 explanation championed by the likes of Collingwood, Dray, Melden Winch, Von 19 Wright and others was in tune with the predominant conception of philosophy as a conceptual enterprise concerned primarily with clarifying different explanatory practices. As this conception of philosophy as an essentially conceptual enterprise became recessive, the purely methodological non-reductivism advocated by defenders 22 of the autonomy of history was accused of ontological escapism and the discussion 23 concerning the autonomy of psychological explanations became the province of the philosophy of mind and action.

Keywords Ontological backlash · Philosophy of history · Philosophy of action

In mid-twentieth century thought the philosophy of history occupied centre stage in key philosophical debates, such as that concerning the nature of action and event explanation. Since the study of history appeared to require an investigative method that is qualitatively different from that of the natural sciences, the philosophy of history became the battleground for a discussion of the action/event distinction in the

This paper was delivered at a workshop on the philosophy of history and historiography organised by Aviezer Tucker at Queen's University Belfast. I am grateful to the audience for helpful comments and suggestions, in particular to Adrian Haddock, Graham Macdonald and Aviezer Tucker.

G. D’Oro $(\bowtie)$

School of Politics, International Relations and Philosophy, Keele University,

Keele, Staffordshire ST55BG, UK

e-mail: g.doro@keele.ac.uk 
guise of a debate for and against methodological unity in the sciences. Whilst in the 34 mid-twentieth century the philosophy of history provided an important forum for the discussion of problems at the very heart of philosophy, the second half of the century has witnessed a steady decline of interest in this sub area. Thus, whilst the debate about the nature of explanation in the natural and human sciences, the so-called verstehen/erklären debate, was a staple diet for undergraduates in the 1960s, this debate now rarely features on the undergraduate syllabus. A cursory look at publications in analytical journals also shows that the debate about the nature of rational and causal explanations is now firmly lodged in the philosophy of mind and action, not in the philosophy of history or the philosophy of social science.

This paper seeks to explain why mainstream analytic philosophy lost interest in the philosophy of history. My key claim is that the declining interest in the philosophy of history is linked to the return of a metaphysical conception of the task of philosophy. Mid-twentieth century philosophy was dominated by a conception of philosophy as conceptual analysis. On this understanding of philosophy the task of the philosopher was to reflect on the explanatory practices of different disciplines and tease out, from these, the regulative principles that govern them. This conception of philosophy provided a fertile ground for the methodological discussions concerning the nature of explanation in the human and natural sciences that took place in the philosophy of history. The second half of the century, by contrast, witnessed a return of "real" metaphysics, a sort of ontological backlash against the idea of philosophy as a form of conceptual analysis. Tired of talk about talk, many philosophers in the latter half of the century turned to substantive questions. Moreover, this return of ontology in the latter half of the century was not a mere adjustment of emphasis within the framework of Kant's Copernican turn, in the manner of phenomenology's slogan "back to the things themselves". The return of ontology in the latter half of the century was a return of real metaphysics, a significant departure from Kant's transcendental turn as well as from the linguistic turn. The declining interest in the philosophy of history is linked to this wider philosophical trend. I should perhaps be very clear about the exact nature of my argument here. First, my claim is not that the philosophy of history is in a crisis. There has been a great deal going on in the philosophy of history since the discussions of the methodological status of historical explanations in the 1960s. ${ }^{1} \mathrm{My}$ claim is rather that, as the philosophical climate changed, and philosophers got increasingly concerned with the ontological implications of the methodological autonomy of the special sciences, they also lost interest in the purely methodological debates about the structure of explanation that unfolded in the philosophy of history in mid-century. Secondly, it is not my goal here to offer an argument for or against a conceptual, as opposed to an ontological, understanding of the task of philosophical enquiry. ${ }^{2}$ My goal is somewhat more limited. It is to explore how the growing

\footnotetext{
${ }^{1}$ The continuing success of History and Theory and the recent launch of the Journal of the Philosophy of History, bear witness to this.

${ }^{2}$ I have argued elsewhere that the ontological standpoint has difficulties in acknowledging the autonomy of the sciences of mind. See my "Idealism and the Philosophy of Mind", Inquiry, 48, 395-412. This argument is also developed in a book manuscript in preparation From a Conceptual Point of View, forthcoming.
} 
interest in ontological questions in the latter half of the century has affected the 74 philosophy of history. The declining fortunes of the philosophy of history in mainstream analytic philosophy, I argue, go hand in hand with a reversal of the order of priority concerning the relation between conceptual analysis and metaphysics. In the methodological discussions concerning the action/event distinction which took place in mid-century, questions of meaning were deemed to be logically prior to questions of truth and questions of metaphysics were linked to questions of method. The debate about the unity or heterogeneity of the sciences was not a debate about the metaphysical possibility of mental causation, but about what it means to explain something as an action or as an event. The debate was treated as a conceptual debate since the method of a science had to do justice to "what" the science sought to explain. By contrast, in the second half of the century, questions of truth come to be regarded as independent from questions of meaning. As a result, metaphysics is disconnected from methodology and reconnected with ontology. Furthermore, in a climate of prevailing naturalism, explanation proper comes to be identified with causal explanation and rationalisations are denied ontological import and deprived of genuine explanatory power. The return of ontology against the background of naturalism thus eliminates the gap between what there is (ontology) and the explanandum of natural science (i.e., what there is in the light of the investigative goals of natural science) and spells the demise of the purely conceptual nature of the action/event distinction that dominated the discussion in the mid-century.

\section{The Golden Age of the Philosophy of History}

The 1960s were a golden age for the philosophy of history. The autonomy of history was defended in the Anglo-American world by thinkers such as Collingwood ${ }^{3}$, Dray $^{4}$, Von Wright ${ }^{5}$, Melden ${ }^{6}$, Wittgenstein ${ }^{7}$ and Winch ${ }^{8}$, to mention a few, as it had once been defended in continental thought by Dilthey, Rickert and Windelbandt. The latter defended the methodological autonomy of history on the ground that the events studied by history, as opposed to those investigated by the natural science, are unique and thus unpredictable. In the Anglo-American world, by contrast, the defence of the methodological autonomy of the historical sciences focussed on the normative character of mentalistic explanation. The historical sciences, it was

\footnotetext{
${ }^{3}$ Collingwood, R. G., The Idea of History, Oxford: Clarendon Press, 1946.

${ }^{4}$ Dray, W. H. (1957). Laws and Explanations in History, London: Oxford University Press, 1957 and "The Historical Explanation of Action Reconsidered", in S. Hook (ed.). Philosophy and History, New York: New York University Press, 1963.

${ }^{5}$ Von Wright, G. H., Explanation and Understanding, London: Routledge and Kegan Paul, 1971.

${ }^{6}$ Melden, A. I., Free Action, London: Routledge and Kegan Paul, 1961.

${ }^{7}$ Wittgenstein, L. Philosophical Investigations, Oxford: Basil Blackwell, 1953 and The Blue and Brown Books, Oxford: Basil Blackwell, 1958.

${ }^{8}$ Winch, P., The Idea of a Social Science and its Relation to Philosophy, London: Routledge and Kegan Paul, 1958 and "Understanding a Primitive Society", American Philosophical Quarterly 1, (1964): 307324.
} The Ontological Backlash: Why did Mainstream Analytic Philosophy Lose Interest in the Philosophy of History? 
argued, are concerned not with events in nature, but with the domain of human affairs, that is, with rational processes or actions, and the explanation of action has a normative element that is absent from the explanation of events. Action explanation, it was claimed, is a species of justification, since it establishes a logical or conceptual relation between the explanans and the explanandum. To explain an action is not to subsume it under a general law derived from observations and empirical generalisation but to rationalise it or render it intelligible. To rationalise an action does not entail sharing the beliefs and goals of an agent but simply showing how the performance of a given action could be deductively derived from certain epistemic and motivational premises 9 . In the Anglo-American tradition the idea of rational reconstruction thus became the key to the thesis of the autonomy of history. Indeed some regarded the issue of uniqueness and lack of predictability as a red herring which distracted attention from what makes history a genuinely autonomous science. If poor predictive power were at the basis of the distinction between the natural and the human sciences, the distinction between the sciences of nature and mind would be merely a distinction in degree, not a distinction in kind, as Mill had indeed argued. According to Mill, ${ }^{10}$ the crucial distinction is not between the sciences of nature and mind but between the exact and inexact sciences, i.e. between those sciences in which strict deterministic predictions are possible and those in which they are not. Since for Mill the distinction between exact and inexact sciences cuts across the distinction between the sciences of nature and mind (meteorology and tidology, which are natural sciences, are also inexact sciences), the distinction between the sciences of nature and mind is not indicative of a significant rift between the method employed to investigate events and the method employed to study the thoughts and actions of human beings. The science of man is an inexact science, but it is nonetheless a science since it employs the same inductive method at work in the natural sciences. In the footsteps of R. G. Collingwood and against this Millian view, Dray argued that what makes history distinctive is not the fact that it investigates unique events with low level predictability, but that it is concerned with actions and that actions differ from events (the subject matter of natural science) because they are expressions of thought to be studied rationally rather than inductively. If history is to have an autonomous domain of enquiry, the distinction between the human and natural sciences must be a distinction in kind, not in degree. It is indeed a distinction in kind because the distinction between the natural and human sciences is a distinction between normative and descriptive sciences, not a distinction between exact and inexact sciences, as Mill claimed.

This golden age of the philosophy of history was dominated by a non-reductivist consensus which came to be epitomised by the slogan "reasons are not causes". During this period to be a non-reductivist was to be a non-causalist and to be a

\footnotetext{
${ }^{9}$ The normativity at work in rational explanation is not specifically moral since there is no need to assume the agent whose action one is trying to understand acts from morally praiseworthy principles; rational explanation is nonetheless a species of justification since a chain of reasoning must be deductively valid in order for the behaviour which expresses it to count as an action.

${ }^{10}$ Mill, J. S. (1843) System of Logic: Ratiocinative and Inductive, in Collected Works of John Stuart Mill, J. M. Robson (ed.), Toronto: University of Toronto Press.
} 
causalist was to be a reductivist. The reductivist (and thus the causalist) view was represented by Hempel, whose seminal 1942 essay, "The Function of General Laws in History" 11 had galvanised the non-reductivist (non-causalist) opposition into action. Hempel argued that historical explanations are structurally isomorphic with explanations in natural science. They only appear to differ because historical explanations are mere "explanation sketches" or arguments with a suppressed general premise. Once the premise is made explicit, it becomes clear that explanations in history have the same logical structure as explanation in natural science and thus that there is a single concept of explanation applicable to both actions and events. It was in response to Hempel that Dray (as an interpreter of Collingwood), Melden, Von Wright Winch and others argued in favour of what came to be known as the "logical connection argument" according to which, since the relationship between the explanans and the explanandum in action explanation is logical or conceptual, reasons cannot be causes.

Since in mid-century non-reductivism was virtually synonymous with noncausalism, to deny the logical connection argument or to assert that "reasons are causes" was tantamount to denying that history is an autonomous science with a distinctive domain of enquiry. This identification of non-reductivism with noncausalism was due to the fact that, in this period, the debate between causalists and non-causalists was essentially a methodological debate about the structure of explanation, not an ontological debate about the possibility of mental causation. The 'unity of the sciences' was understood to mean, the methodological unity of the sciences. To deny the slogan "reasons are not causes" thus entailed abandoning nonreductivism. Both causalists, such as Hempel and Gardiner, ${ }^{12}$ and non-causalists, such as Dray, Melden and Von Wright, were agreed about the nature of the debate, that is, about its methodological nature and about the role of the philosopher in such a debate, even if they disagreed about the thesis of the unity or heterogeneity of the sciences. The role of the philosopher was to provide a second order reflection on the nature of explanation in different forms of enquiry and to assess whether such differences were distinctive enough to legitimise talk of different sciences. As we shall see, it is this consensus about the essentially methodological nature of the reasons/causes debate that came to be questioned in the latter part of the twentieth century and it is this questioning that eventually spelt the demise of the philosophy of history as a forum for the discussion of the relation between action and event explanation. As the debate acquired an ontological dimension which was absent from the methodological framework of the 1960s, discussions of the unity/disunity of the sciences and of the action/event distinction gradually moved from the philosophy of history and social science to the philosophy of mind and action, where they took the form of a debate about the metaphysical possibility of mental causation, rather than about the methodological autonomy of action explanation.

\footnotetext{
${ }^{11}$ Hempel, C., "The Function of General Laws in History", Journal of Philosophy, 39, 35-48, 1942. DOI $10.2307 / 2017635$.

${ }^{12}$ Gardiner, P., The Nature of Historical Explanation, Oxford University Press, 1952.
} 
In the latter half of the twentieth century many came to question the purely 185 methodological framework of the reductivism/non-reductivism debate that had 186 dominated in mid century. Foremost amongst such critics is J. Kim, who denounced 187 attempts to eschew the ontological dimension of the reasons/causes distinction as an 188 attempt to find a quick and easy solution to the mind-body problem. Against the 189 view that the relation between body and mind is a relation between explanatory 190 practices, Kim argues as follows:

One sort of reaction on the part of some philosophers to the re-emergence of mental causation as a philosophical problem is to try to dissipate it by arguing that there is in fact no such "problem"... It has been argued that worries about mental causation arise out of our misplaced philosophical priorities; that overindulgence in unmotivated metaphysical assumptions and arguments is the source of the unnecessary worries; that a misunderstanding of the logic and metaphysics of causation is at the core of the apparent troubles; that we should look to explanations and explanatory practices, not to metaphysics, for guidance on the matter of mental causation... These are what we might call "free lunch" solutions - or, if not free, at least pretty cheap ones. ${ }^{13}$

Kim's argument here is directed against the few existing contemporary proponents of the methodological thesis, ${ }^{14}$ but is equally an attack against the methodological conception of the reasons/cause debate that underpinned the logical connection argument.

In a similar vein $\mathrm{T}$. Crane argues that what is at stake in the reasons/causes debate is not the relation holding between different forms of explanation, but the relation between the methodological question of explanation and the ontological question of causation. The physicalist commitment to explanatory closure entails that not all explanations have ontological import and thus that some explanation must have a metaphysical edge over others:

The issue is one about causation, not explanation. There are many ways of explaining events and processes in the physical world; but if the completeness of physics is true, then there is one special kind of cause. To state the problem, then, requires us to distinguish between causation and explanation, since the completeness of physics is a claim about causation. ${ }^{15}$

Even more provocatively, E. Lepore and B. Lower dismiss the non-causalist consensus that underpinned a commitment to the logical connection argument as the "era of little red books" - a reference to the colour of the cover of the Routledge and

\footnotetext{
${ }^{13}$ Kim, J., Mind in a Physical World, Cambridge, Massachusetts: MIT Press, 1998, p. 59.

14 See Baker, L.R. "Metaphysics and Mental Causation", in Mental Causation, edited by J. Heil and A. Mele, Oxford: Oxford Clarendon Press, 1993 and Burge, T. "Mind-Body Causation and Explanatory Practice", also in Mental Causation, edited by J. Heil and A. Mele. Oxford: Oxford Clarendon Press, 1993.

${ }^{15}$ Crane, T., Elements of Mind, Oxford University Press, 2001, p. 60. 
Kegan Paul series in which Winch's "The Idea of a Social Science" and similar oriented defences of the autonomy of social science explanation appeared: ${ }^{16}$

During the heyday of neo-Wittgenstenian and Rylean philosophy of mind, the era of little red books, it was said that propositional attitude explanations are not causal explanations and that beliefs, intendings, imaginings, and the like are not even candidates to be causes. Indeed, to treat mentalistic language as describing causes or causal processes is, it was said, a logical error. We have come a long way since then. The work of Davidson, Armstrong, Putnam, and Fodor (among others) has reversed what was once the orthodoxy and it is now widely agreed that propositional attitude attributions describes states and episodes which enter into causal relations. ${ }^{17}$

The received view of the latter half of the twentieth century is that the reasons/ causes debate has an ontological dimension which was simply overlooked by a generation of philosophers in the grips of an 'ordinary language' fashion. The argument against the logical connection argument was given its first iconical formulation by Davidson in "Actions, Reasons and Causes", ${ }^{18}$ an essay which has changed the way in which philosophers think about the very nature of the mind-body problem. It is to Davidson that I shall turn in the next section.

\section{Davidson and the New Face of Non-reductivism}

It was Davidson who changed the face of non-reductivism. In the mid twentiethcentury to be a non-reductivist was tantamount to being a non-causalist. Since the debate was of a methodological nature, defending the autonomy of history entailed showing that the logical structure of action explanations differs from that of causal explanations. Once the work of conceptual clarification was done, the philosopher's job was over. There were no residual ontological questions to be addressed. Davidson by contrast argued both a) that mentalistic explanations have a normative element that is absent from naturalistic explanations and thus that the sciences of mind are methodologically autonomous from the sciences of nature and b) that rational explanations are species of causal explanations, and as such, they are not ontologically inert. The first claim makes him a methodological non-reductivist, the second makes him a causalist. Davidson thus denied the slogan that "reasons are not causes" whilst still defending a form of non-reductivism. He claimed nonreductivism to be compatible with causalism.

Davidson's identification of reasons with causes was deemed to have two main advantages over the logical connection argument advocated by the previous

\footnotetext{
${ }^{16}$ Graham MacDonald pointed out to me that the logical connection argument came to be referred as "The Routledge and Kegan Paul" argument after the series which published the work of many of its exponents.

${ }^{17}$ Lepore, E., and B. Lower, "More on Making Mind Matter" Philosophical Topics XVII (1), pp. 175191,1989

${ }^{18}$ Davidson, D., "Actions, Reasons and Causes". Journal of Philosophy, 60, 685-700, 1963. Reprinted in his Essays on Actions and Events, Clarendon Press, 1980 and in A. R. Mele (ed.), The Philosophy of Action, Oxford: Oxford University Press, 1997, pp. 3-21.
} 
generation of non-reductivists. First, the introduction of the notion of causally efficacious reasons seemed to be doing justice to the agent's internal monologue. For the previous generation of non-reductivists to explain an action is to rationalise it, to provide reasons in the light of which the action could be rendered intelligible. Such a process of rational reconstruction appeared completely to bypass the agent's own psychological processes. The introduction of the notion of causally efficacious reasons enabled Davidson to isolate the reasons which formed part of the agent's internal monologue from mere rationalisations thereby doing justice to the first person perspective. Secondly and more importantly for the purposes of this discussion, Davidson's identification of reasons with causes seemed to provide a solution to the problem of epiphenomenalism. Davidson argues that if reasons were not causes (as the previous generation of non-reductivists believed), rational explanations would remain metaphysically inert. If, as supporters of the logical connection argument claimed, the relation between the explanans and the explanandum in mentalistic explanations is purely logical or conceptual, then rational explanations are propositions which express, to use a Humean phrase, relations of ideas and, as such lack existential or ontological import. ${ }^{19}$

Davidson agrees with a previous generation of non-reductivists that the sciences of mind are methodologically autonomous. In this respect he sides with Dray, Melden, Von Wright and others against Hempel. On the other hand, Davidson disagrees with the previous generation of non-reductivists because he believed they failed to address the problem of mental causation, thereby ignoring the ontological dimension of the action/event distinction. Yet, to say that the older generation of non-reductivists failed to address the ontological dimension of the action/event distinction is to beg the very question at issue, i.e., whether the debate is of an ontological rather than a conceptual nature. The older generation of non-reductivists would have argued that, far from neglecting the ontological dimension of the mindbody problem, they had deliberately refrained from answering the metaphysical question of mental causation since answering such a question required applying the explanations of one science to the explanandum of another, thereby committing a category mistake. In other words, the older generation of non-reductivists would have argued that their refusal to address the question of mental causation was not a failure to engage with ontology, but a principled choice grounded in the belief that since method and metaphysics are intimately related, existential questions must be addressed within a prior horizon of meaning. Davidson's claim that the earlier generation had neglected the ontological dimension of the action/event distinction is ultimately due to the fact that he does not share the conception of philosophy as a form of conceptual analysis that informed the defence of non-reductivism in the midtwentieth century. To endorse Davidson's objection therefore, one must be prepared to reject the conception of philosophy as a second order reflection on first order knowledge and to be willing to ascribe a different role to it.

\footnotetext{
${ }^{19}$ I have discussed the alleged advantages of Davidson's causalist position vis-à-vis the logical connection argument in several essays including "Collingwood, Psychologism and Internalism", European Journal of Philosophy 12:2, 2004, pp. 163-177; "Two Dogmas of Contemporary Philosophy of Action", Journal of the Philosophy of History 1, pp. 11-26, 2007 and "In Defence of the Agent-Centred Perspective", Metaphilosophy 36, pp. 652-667, 2005. DOI 10.1111/j.1467-9973.2005.00398.x.
}

Springer

The Ontological Backlash: Why did Mainstream Analytic Philosophy Lose Interest in the Philosophy of History? D'Oro G 
Davidson develops his non-reductivism within the framework of a naturalistic conception of reality which grants ontological priority to the explanatory framework of natural science. ${ }^{20}$ Davidson, in other words, presupposes that explanation proper is causal because only causal as opposed to rational explanations have existential import. Assuming that natural science explanations have the ontological edge over other forms of explanation, Davidson asks how is it possible to justify our commitment to the ontological priority of scientific explanation with our continued employment of rational explanations. He ruled out both interactionist dualism and psychophysical parallelism as possible solutions to the mind-body problem and argued instead for a form of dual-aspect monism according to which mental events are causally efficacious in so far as they are described as physical events. Mental events may thus be seen as causally efficacious (not epiphenomenal) in a way that does not interfere with the modern scientific commitment to the completeness of physics. Davidson's 'anomalous monism' seeks to solve the problem of the epiphenomenality of the mental which, in his view, plagued the non-reductivism of the older generation, without violating the assumption so dear to most contemporary physicalists, namely the causal closure of the physical. ${ }^{21}$ Many have been unpersuaded by Davidson's solution, but most, if not all, have been persuaded by his overall approach to the problem and have accepted that any defence of the non-reducibility of action to event explanation must account for how is it possible to do justice to the autonomy of the mental against the background of a naturalistic conception of reality. In this respect Davidson's contribution has been extremely influential for he has transformed the very nature of the problem posed by the action/ event distinction from a purely conceptual problem about the nature of explanation to a metaphysical problem about the possibility of mental causation. Thus, although Davidson may have failed to convince many that he found a solution to the problem of mental causation, ${ }^{22}$ he has been extremely successful in determining the kind of questions that ought to be addressed and thereby in changing the understanding of the philosopher's role from that of reflecting on the nature of explanation in different

\footnotetext{
${ }^{20}$ The metaphysical underpinnings of Davidson's non-reductivism are developed in his "Mental Events" in Essays on Actions and Events, Oxford and New York: Oxford University Press, 1980.

${ }^{21}$ I have argued elsewhere that the problem of epiphenomenalism is generated by Davidson's ontological approach in conjunction with a layered view of science in which rational explanations are said to supervene upon causal explanations. See "Idealism and the Philosophy of Mind" Inquiry 48/5, 2005, pp 395-412. DOI 10.1080/00201740500241847.

${ }^{22}$ Some argue that anomalous monism is vulnerable to the charge of epiphenomenalism. For the epiphenomenalist objection see Honderich, T., "The Argument for Anomalous Monism", Analysis 42, 1982, pp. 59-64 and "Smith the Champion of Mauve", Analysis 44, 1984, pp. 86-87. See also Sosa, E., "Mind-Body Interaction and Supervenient Causation" Midwest Studies in Philosophy 9, 1984, pp. 271-81. Others argue that anomalous monism must either accept epiphenomenalism or reckon with the problem of explanatory exclusion. This dilemma has been explored by Kim, J., "The Myth of Non-reductive Materialism", Proceedings of the American Philosophical Association 63, 1989, pp. 31-47; Kim. J., "Explanatory Exclusion and the Problem of Mental Causation", in Information, Semantics and Epistemology, edited by E. Villanueva. Cambridge Massachusetts: Basil Blackwell, 1990; Kim, J. "The Nonreductivist's Trouble with Mental Causation", in Supervenience and the Mind, Cambridge University Press, 1995; Sosa, E., "Davidson's Thinking Causes" in Mental Causation edited by J. Heil and A. Mele, Oxford: Oxford Clarendon Press, 1993.
} 
domains of enquiry to that of accommodating folk-psychological explanations within the conception of reality that dominates the natural sciences.

In the latter half of the century the convergence of a renewed interest in ontology and the prevailing perspective of natural science has led to a very different understanding of what is required to defend the autonomy of the special sciences. Whilst in the methodological debates which occurred in mid-century defending the autonomy of history required showing that history has a distinctive method that is non-reducible to explanation in natural science, in the second half of the century to defend the autonomy of history entails showing how it is possible to maintain certain conceptual and methodological distinctions in the light of a non negotiable commitment to the ontology of natural science. Davidson was a leading figure in this new Zeitgeist. He changed the face of non-reductivism because he did not share the conception of philosophy which united the previous generation of nonreductivists. His non-reductivism is developed not against the background of a conception of philosophy as offering a meta-level reflection on first order sciences, but against the backdrop of a conception of philosophy as the underlabourer of science whose task is to account for how certain methodological and conceptual distinctions may still be possible in the context of the ontological priority of natural science.

In the early 1960s the philosophy of action had yet to be recognised as a distinctive area of philosophy. As we have seen, the action/event distinction was firmly located within the philosophy of history and the philosophy of the social science. With the publication of "Actions, Reasons and Causes" the so-called verstehen/erklären debate had found a new home in a freshly established branch of philosophy. Yet, as the debate moved from the philosophy of history to the philosophy of action, it also changed from a methodological debate about the structure of explanation in the sciences of mind and nature to an ontological debate about the possibility of mental causation. Davidson was largely responsible for altering the terms of the debate and for setting the new philosophical agenda. After Davidson, and indeed as a result of Davidson, reductivists and non-reductivists are no longer to be found on either side of the causalist/non-causalist divide since nonreductivism is no longer associated with an essentially methodological claim. In spite of being the principal architect of a new causalist consensus uniting reductivists and non-reductivists alike, Davidson still remains faithful to a central tenet of the logical connection argument for he kept alive the idea that the sciences of mind are distinctive because mentalistic explanations have a normative dimension that finds no echo in the natural world. In fact, whilst non-reductivism has dominated the philosophy of mind in the latter half of the twentieth century many of the nonreductivist positions available have failed to do justice to the kind of problematics that inspired the defence of the autonomy of the sciences of mind articulated by Collingwood, Dray, Melden and others. The most widespread form of nonreductivism, the kind of multiple realisation functionalism espoused by Putnam ${ }^{23}$

${ }^{23}$ Putnam, H., "The Nature of Mental States" in H. Putnam, Collected Papers II, Cambridge: Cambridge University Press, 1975.

Springer

The Ontological Backlash: Why did Mainstream Analytic Philosophy Lose Interest in the Philosophy of History? D'Oro $\mathrm{G}$ 
and Fodor, ${ }^{24}$ flatly fails to acknowledge the existence of a distinction in kind between the sciences of nature and mind. Psychology, for Fodor, differs from physics not because it is a normative science but because psychological laws, unlike those of the basic sciences, are hedged by ceteris paribus clauses. ${ }^{25}$ For Fodor, as indeed for Mill, the crucial distinction is not between psychology and physics, but between physics and the rest of the special sciences. Fodor, very much like Mill before him, regards the sciences of mind as empirical sciences on a par with other special sciences such as geology, and claims that psychology, like the rest of the special sciences, is to be distinguished from physics not because it is normative but because its laws are incapable of yielding precise predictions. Thus, although Davidson rejected the purely methodological dimension of the reasons/causes debate, he did not reject the view, characteristic of the first generation of nonreductivists, that the distinction between the sciences of mind and nature is a distinction in kind rather than in degree, and thus the view that there is a genuine methodological distinction to be reckoned with, whatever one's metaphysical commitments might be.

\section{Ontological Seriousness and Honest Philosophizing}

The contemporary consensus is that philosophy must take the ontological, not the conceptual point of view. As John Heil puts it:

The twentieth century was not kind to metaphysics. In the English speaking world metaphysics was deflated by neo-Kantians, logical positivists, logical empiricists, as well as philosophers who regarded the study of ordinary language as a fitting replacement for traditional philosophical pursuits. Elsewhere philosophers promoting phenomenology, hermeneutics, and existentialists creeds showed themselves equally disdainful of tradition. Metaphysical talk was replaced by talk about metaphysical talk; concern with conceptual schemes and patterns of ontological commitment supplanted concern with ontology... I want only to note the inescapability of ontology. Honest philosophy requires what the Australians call ontological seriousness. ${ }^{26}$

The decline of interest in the philosophy of history within mainstream analytic philosophy, I have argued, is linked to this ontological backlash against the conceptual standpoint that dominated the early generation of non-reductivists. It is because the mind-body debate as discussed within the philosophy of history and social science entailed taking the conceptual point of view that the discipline is no

\footnotetext{
${ }^{24}$ See Fodor J. A., "Making Mind Matter More", Philosophical Topics XVII, pp. 59-79, 1989 and "Special Sciences: Still Autonomous after All These Years", Philosophical Perspectives 11, 149-63, 1997.

${ }^{25}$ See Fodor 1989.

${ }^{26}$ Heil, J., From an Ontological Point of View, Oxford: Clarendon Press, 2003, p. 1-2.
} 
between the first and second generation of non-reductivists goes to the very heart of philosophy since choosing one approach or the other entails making quite significant decisions about the relation between method, meaning and metaphysics. Should metaphysics be identified with ontology and disconnected from questions of meaning and method? Those who dismiss the purely conceptual nature of the action/event distinction tend to do so because they share a conception of philosophy as an essentially ontological enquiry. Yet, whether metaphysics should be identified with ontology and disconnected from questions of meaning and method, as Heil claims, or whether metaphysics should be disconnected from ontology and connected with method and meaning in the manner of either Kant's metaphysics of experience or Collingwood's metaphysics of absolute presuppositions, ${ }^{27}$ is exactly what is at stake in the transition from the first to the second generation of nonreductivists. It certainly should not be enough to proclaim that serious philosophising requires taking the ontological point of view without further ado. What is required is a serious engagement between the ontological and the conceptual point view, an honest attempt to establish what is the order of priority between logic and ontology, method and metaphysics, truth and meaning. Without a serious engagement with these fundamental questions the call for ontological seriousness will remain ungrounded, and its exponents could indeed be charged with being in the grip of a new philosophical fashion.

The thesis of this paper has been primarily descriptive. I have not argued in favour of a particular conception of the philosophy of history or in any way tried to dictate what its subject matter is or should be. I have simply tried to show (1) that the debate concerning the relation between action and event explanation, which in the 1960s was firmly lodged in the philosophy of history, has migrated to the philosophy of mind and action; (2) that in the course of this migration the debate has changed from one addressing the methodological autonomy of action explanation to one addressing the metaphysical possibility of mental causation and (3) that as the view that no solution to a philosophical problem should omit a discussion of its ontological commitments took hold, mainstream analytic philosophy lost interest in the generation of non-reductivists who sought to defend the non-reducibility of action explanation to event explanation by arguing that history has an autonomous domain of enquiry that is distinct from that of the natural sciences.

Nonetheless, it would be inappropriate to conclude this discussion without addressing a possible objection that may be raised against the conception of the task of the philosophy of history presupposed by philosophers such as Collingwood and Dray. It could be argued that there is more to the subject matter of history than actions, and that the range of questions addressed by the philosophy of history goes far beyond the conceptual issues which are captured by the reasons/causes debate. This complaint is understandable. When doing philosophy we distinguish on the one hand between the philosophy of mind, the philosophy of science, the philosophy of

${ }^{27}$ Collingwood, R. G., An Essay on Metaphysics, Oxford: Clarendon Press, 1940; revised edition, with an introduction by Rex Martin, Oxford: Oxford University Press, 1998. 
religion, the philosophy of history and, on the other, between conceptual analysis, ontology and epistemology. These distinctions carve the territory in very different ways. The philosophy of mind, the philosophy of religion and the philosophy of science cover a range of conceptual, ontological and epistemological problems. This is the case also with the philosophy of history which is concerned not only with conceptual questions of the kind outlined in this paper but also with a range of epistemological challenges which arise from the fact that the past, unlike the present, is not available for observation and that historical explanations must rely on evidence. ${ }^{28}$ Whether the philosophy of history is primarily a hermeneutic enterprise concerned with the interpretation of actions or an epistemological venture whose goal is to show how we acquire knowledge of the past is, it seems to me, a debate internal to the philosophy of history in the way in which the question as to whether the mind-body problem is a problem about the interaction of distinct ontological substances, an epistemological problem arising from the fact that we have very different modes of access to our mental and physical states, or a problem about the relationship between normative and descriptive sciences, is a debate that reflects very different conceptions of the nature of the mind-body problem within the philosophy of mind. Those philosophers such as Collingwood and Dray, who articulated a non-reductivist thesis within the philosophy of history, believed that the contrast between the past and the present fails to delineate a subject matter for historical enquiry that is sufficiently distinct from that of the natural sciences and thus argued that the relevant distinction to be made in order to safeguard the autonomy of historical explanation is not between the past and the present, but between actions and events and their respective modes of explanations: rational and causal. For philosophers such as Collingwood and Dray history is an autonomous science not in so far as it deals with the past rather than the present but in so far as it is concerned with the interpretation of actions rather than the causal explanation of events. History, in their view, has a distinctive domain of enquiry because it is a hermeneutic science. My goal here, however, was not to take sides in a debate within the philosophy history in support of the view that history is a primarily a hermeneutic science, but rather to show that whether or not the identification of historical explanations with rational explanations is correct, the thesis that action explanations are rational explanations, which are conceptually irreducible to event explanations, struck a note with the wider philosophical community and brought the philosophy of history to the attention of mainstream analytic philosophy. Conversely, I have argued, interest in the philosophy of history waned as the philosophical Zeitgeist changed and the generation of non-reductivists who construed the action/event distinction in purely conceptual terms, thus refusing to go beyond a purely methodological dimension of the reasons/causes debate, were deemed to be evading the metaphysical dimension of the action/event distinction and were consequently accused of ontological escapism.

${ }^{28}$ Some indeed might go so far as identifying the philosophy of history with a "branch of epistemology". See A. Tucker, Our Knowledge of the Past, Cambridge, Cambridge University Press, 2004, p. 11. 


\section{AUTHOR'S PROOF}

The original publication is available at www.springerlink.com

\section{AUTHOR QUERY}

\section{AUTHOR PLEASE ANSWER QUERY.}

No Query. 